\title{
Stimulus or stimulation: Relevant cues in a learning situation involving differences in light reinforcement
}

\author{
E. WELDON \\ INSTITUTE OF PSYCHIATRY, UNIVERSITY OF LONDON
}

Rats of the Maudsley Reactive and Nonreactive strains were used in two light reinforcement experiments in a Skinner Box with two levers. Different response contingencies were compared in order to test the relative validity of the "stimulus change" and "preference" theories. The results did not support the preference theory, but are consistent with the stimulus change theory.

A number of recent reports in the literature have shown that stimuli apparently irrelevant to basic drives such as hunger, thirst, sex, etc. can be reinforcing. Several authors (e.g., Girdner, 1953; Kish, 1955; Marx, Henderson \& Roberts, 1955) have shown that rats will learn to press the lever in a Skinner box without food or water reinforcement when the pressing of the lever produces changes in illumination in the box. Such changes constitute sensory reinforcement of the kind postulated by Kish (1955) in the hypothesis of "sensory reinforcement," which states that response-contingent stimulation in any modality is reinforcing.

Two theories have been advanced to account for this phenomenon. One of these, in terms of stimulus change (Forgays \& Levin, 1959), states that the reinforcing properties of response-contingent stimuli are attributable to the stimulus change, so that light-onset and light-offset would be equally reinforcing. The other, the preference theory (Lockard, 1963), places little emphasis upon the change in stimulation but stresses the preferred stimulus.

Several aspects of sensory reinforcement have been examined by various authors. Hurwitz (1956) compared a group of Ss in a light-onset situation with another group in a light-offset situation. Forgays \& Levin (1959) showed that Ss learned to discriminate the light reinforcement effect contingent on one of two levers in a Skinner box. Lockard (1966) studied light preference behavior and compared light-onset, offset, increase, and decrease, also using a box with two levers. Williams \& Lowe (1967) compared the effectiveness of a steady vs a flickering light. Most of these authors interpreted their findings to be not inconsistent with stimulus change theory, but Lockard in particular favored an explanation in terms of the preferred stimulus.

The present investigation is designed to test the relative validity of the two theories. It consists of two related experiments. In the first of these, the Skinner box had two levers, one of which rendered a normally dim houselight "bright," while the other lever switched the light off. In the second experiment, one lever switched on the light while the other was a dummy that had no effect on the light intensity.

\section{Experiment 1}

The Ss were 20 rats from the Maudsley Reactive (MR) and 20 rats from the Maudsley Nonreactive (MNR) strains, equally balanced between the sexes, all aged between 104 and 161 days at the beginning of the experiment. The apparatus consisted of a modified Behaviour Apparatus Skinner box and modular control rack. The box was fitted with two levers, a houselight, but no food trough. This box was placed inside a doublewalled sound-insulating cabinet, which was fitted with an air-blower that provided ventilation but served also as a soundscreen. The Ss were placed individually into the apparatus at the same time each day on five consecutive days for periods of $30 \mathrm{~min}$.

The frequency of lever presses for each of the two levers was recorded and an analysis of variance carried out. This showed no significant main effects between groups (i.e., for sex and strain), and also no significant main effect within groups (i.e., for one lever as against the other). The lever-strain interaction was found to be significant just below the $1 \%$ level $(F=7.27, d f=1 / 36)$, but all other interactions were not significant at an acceptable level. The results suggest that the Ss were either pressing the levers randomly, or pressing in order to obtain a change in stimulation. To distinguish between these, another experiment was carried out, in which one lever switched on the light, while the other lever was a dummy.

\section{Experiment 2}

In this experiment the Ss consisted of six rats from the Maudsley Reactive strain and six rats from the Maudsley Nonreactive strain, equally balanced between the sexes. All were aged between 112 and 153 days at the beginning of the experiment. The apparatus and procedure were the same as in the previous experiment, except that pressing one lever switched the houselight "on," while the second lever (dummy) did not affect the illumination.

As in the previous experiment, an analysis of variance was computed. Again, there were no significant main effects between groups (i.e., for sex and strain). But the main effect within groups (i.e., for one lever as against the other) was significant at the $5 \%$ level $(F=7.82, d f=1 / 8)$, and the lever-strain interaction also 
reached this level of significance $(F=5.92, d f=1 / 8)$. The remaining interactions were not significant at an acceptable level. The results showed that the lever which caused changes in the level of illumination was pressed more frequently than the dummy lever.

\section{Discussion}

The object of the experiment was to examine the relative merits of the stimulus change and preference theories as explanations of response-contingent light reinforcement. Comparisons were made between the two pairs of reponse-contingent light intensities, the first affording a choice of changing the houselight intensity to either a brighter or a dimmer level. The second involved the choice of lever-pressing for lightonset or pressing without affecting the illumination. The results showed that in terms of the frequencies of lever-pressing, there was little preference between making the houselight brighter or dimmer. However, a markedly greater number of responses was associated with light-onset than with the dummy lever. Thus, pressing the dummy lever was not so reinforcing, so that the Ss would seem to use the levers to obtain a change of stimulation. The fact that the lever main effect in the analysis of variance of Experiment 1 was not significant, whereas it was in the analysis of Experiment 2 , would suggest that it is a change in stimulation that motivates the animal and provides the sensory reinforcement.

The lever-strain interaction was significant in both analyses. The MNR strain tended to press the lightbright and light-onset levers more frequently than the MR strain; whereas the MR strain tended to press the light-offset and dummy levers more often than the MNR strains. Responses involving light-onset have been interpreted by Hurwitz (1956) and Robinson (1959) in terms of the "scanning hypothesis." The light is said to produce illumination that enables the $S$ to scan its environment; i.e., stimulation is received both from the light itself and from the illuminated environment. Since scanning of the environment is equated with exploration, the foregoing is in agreement with the known strain differences in the open-field test (Broadhurst \& Eysenck, 1964); of the two strains, the nonreactives show a greater degree of ambulation and exploration.

It could be said that the animals exhibited a "stimulus hunger" as described by Eysenck(1965), i.e., a tendency to seek out stimulation. The animals tended to press the levers which affected the existing level of illumination rather than the dummy lever. There may be individual differences in stimulus hunger, which could be investigated in further experiments using a larger number of Ss.

The results of each of the two experiments described are open to several interpretations. Taken separately, Experiment 1 could be explained in terms of a generalized tendency for pressing levers, and Experiment 2 by a preference for light over darkness. Neither of these explanations satisfies the results of both experiments taken together, so that the preference theory is not hereby supported. However, the results are consistent with the stimulus change theory, in that the Ss are gratified through response-contingent reinforcement.

\section{References}

BROADHURST, P. L., \& EYSENCK, H. J. Interpretation of exploratory behaviour in the rat. In H. J. Eysenck (Ed.), Experiments in Motivation. London: Pergamon Press, 1964, pp. 375-389.

EYSENCK, H. J. Fact and Fiction in Psychology. London: Penguin, 1965.

FORGAYS, D. G., \& LEVIN, H. Discrimination and reversal learning as a function of change of sensory stimulation. J. comp. physiol. Psychol., 1959, 52, 191-194.

GIRDNER, J. B. An experimental analysis of the behavioral effects of a perceptual consequence unrelated to organic drive states. Amer. Psychologist, 1953, 8, 354-355. (Abstract).

HURWITZ, H. M. B. Conditioned responses in rats reinforced by light. Brit. J. Anim. Behav., 1956, 4, 31-33.

KISH, G. B. Learning when the onset of illumination is used as reinforcing stimulus. J. comp. physiol. Psychol., 1955, 48, 261-264.

LOCKARD, R. B. Several tests of stimulus-change and preference theory in relation to light-controlled behavior in rats. J. comp. physiol. Psychol., 1966, 62, 415-426.

MARX, M. H., HENDERSON, R. L., \& ROBERTS, C. L. Positive reinforcement of the bar pressing response by a light stimulus following dark operant pretests with no after-effect. J. comp. physiol. Psychol., $1955,48,73-76$.

ROBINSON, J. S. Light onset and termination as reinforcers for rats living under normal light conditions. Psychol. Rep., 1959, 5, 793-796.

WILLIAMS, D. I., \& LOWE, G. Bar pressing in the rat as a function of variable visual stimulation. Psychon. Sci., 1967, 7, 231-232.

Notes

1. The author is indebted to Professor H. J. Eysenck, at whose suggestion the research was instigated. Grateful thanks are also due to Dr. H. C. Holland for his helpful comments and criticisms.

2. The research was supported by a grant from the Bethlem Royal Hospital and Maudsley Hospital Research Fund. 